\title{
Fate of hematopoietic stem cells determined by Notch1 signaling (Review)
}

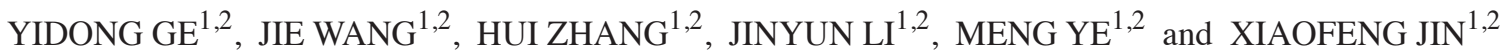 \\ ${ }^{1}$ The Affiliated Hospital of Medical School, Ningbo University, Ningbo, Zhejiang 315020; \\ ${ }^{2}$ Department of Biochemistry and Molecular Biology, and Zhejiang Key Laboratory of Pathophysiology, \\ Medical School of Ningbo University, Ningbo, Zhejiang 315211, P.R. China
}

Received August 21, 2021; Accepted November 17, 2021

DOI: $10.3892 / \mathrm{etm} .2021 .11093$

\begin{abstract}
Regulation of the fate of hematopoietic stem cells (HSCs), including silencing, self-renewal or differentiation into blood line cells, is crucial to maintain the homeostasis of the human blood system and prevent leukemia. Notch1, a key receptor in the Notch signaling pathway, plays an important regulatory role in these properties of HSCs, particularly in

Correspondence to: Dr Xiaofeng Jin or Dr Meng Ye, The Affiliated Hospital of Medical School, Ningbo University, 818 Fenghua Road, Ningbo, Zhejiang 315020, P.R. China

E-mail: jinxiaofeng@nbu.edu.cn

E-mail: yemeng@nbu.nbu.edu.cn
\end{abstract}

Abbreviations: AA, aplastic anemia; AGM, aortagonadal-mesonephric; ALL, acute lymphoblastic leukemia; allo-HSCT, allogeneic hematopoietic stem cell transplantation; AML, acute myelogenous leukemia; auto-HSCT, autologous hematopoietic stem cell transplantation; bHLH, basic helix-loop-helix; CLL, chronic lymphoblastic leukemia; CML, chronic myelogenous leukemia; DLL, Delta-like; EE, early endosome; EGF, epidermal growth factor; EHT, transformation of hematopoietic endothelial cells into hematopoietic stem cells and progenitor cells; ESCRT, endosomal sorting complexes required for transport; ETP, T-cell precursor; E1, ubiquitin-activating enzyme; E2, ubiquitin-conjugating enzyme; E3, ubiquitin ligase; Fbxw7, F-box and WD repeat domain containing 7; GVHD, graft-vs.-host disease; HD, heterodimerization; HSCs, hematopoietic stem cells; HSCT, hematopoietic stem cell transplantation; hSel-10, human Sel-10; ILVs, interluminal vesicles; MDS, myeloproliferative disorders; ME, maturing endosome; MM, multiple myeloma; MSCs, mesenchymal stem cells; MVBs, multivesicular bodies; NECD, Notch extracellular domains; NHL, Non-Hodgkin's lymphoma; NICD, Notch intracellular domains; N1ICD, Notch1 intracellular domain; OSCs, oligopotent stem cells; PSCs, pluripotent stem cells; P-SP, para-aortic splanchnopleure; TAD, transactivation domain; T-ALL, T-cell acute lymphoblastic leukemia; TSCs, totipotent stem cells; Ub, ubiquitin; UPS, ubiquitin-proteasome system; USCs, unipotent stem cells; YS, yolk sac

Key words: hematopoietic stem cell, Notch1, ubiquitination, stemness, T-cell acute lymphoblastic leukemia, ubiquitin ligase the maintenance of the stemness of HSCs. In recent decades, the ubiquitination modification of Notch1 has been gradually revealed, and also demonstrated to affect the proliferation and differentiation of HSCs. Therefore, a detailed elucidation of Notch1 and its ubiquitination modification may help to improve understanding of the maintenance of HSC properties and the pathogenesis of leukemia. In addition, it may aid in identifying potential therapeutic targets for specific leukemias and provide potential prognostic indicators for HSC transplantation (HSCT). In the present review, the association between Notch1 and HSCs and the link between the ubiquitination modification of Notch1 and HSCs were described. In addition, the association between abnormal HSCs mediated by Notch1 or ubiquitinated Notch1and T-cell acute lymphoblastic leukemia (T-ALL) was also examined, which provides a promising direction for clinical application.

\section{Contents}

1. Introduction

2. Overview of the Notch pathway

3. Notch1 and HSCs

4. Notch1 and ubiquitination

5. Clinical application

6. Conclusions and perspectives

\section{Introduction}

Stem cells are undifferentiated cells that have the ability to proliferate (self-renewal) both in vitro and in vivo and differentiate into mature specialized cells (1). Stem cells can be divided into five groups: Totipotent stem cells (TSCs), pluripotent stem cells (PSCs), multipotent stem cells, oligopotent stem cells (OSCs) and unipotent stem cells (USCs) (2). TSCs have the highest differentiation potential, able to produce an entire living organism on their own, and most notably a zygote. PSCs can form cells in all the germ layers, with the exception of the cells that form structures outside the embryo, and embryonic stem cells are a prime example. Multipotent stem cells can produce certain lineages of cells, and the majority of adult stem cells are multipotent, including hematopoietic stem 
cells (HSCs), mesenchymal stem cells (MSCs), and other adult progenitor cells (3). OSCs can differentiate into numerous cell types, such as bone marrow stem cells which may develop into white blood cells but not red blood cells. Eventually, USCs may form only one cell type, such as skin cells.

Among multipotent stem cells, HSCs are the most common multipotent stem cells with the ability to maintain homeostasis by self-renewal or differentiation into all blood cell lineages (4). The stemness of the HSCs combines the ability of the HSCs to perpetuate its lineage, to produce differentiated cells (such as lymphocytes and granulocytes) and to interact with the hematopoietic microenvironment to maintain a balance between quiescence, proliferation, and regeneration (5). In short, the stemness of HSCs helps maintain the homeostasis of the blood system by balancing the proliferation and differentiation of HSCs. When the stemness of HSCs is destroyed, abnormal production of blood cells occurs and further abnormal blood system tumors are produced, namely leukemia (6). Common subtypes of leukemia include acute myelogenous leukemia (AML), acute lymphoblastic leukemia (ALL), chronic myelogenous leukemia (CML) and chronic lymphoblastic leukemia (CLL). Therefore, a full understanding of the signaling pathways or regulatory factors that are capable of regulating the stemness of HSCs may provide further insight into HSCs and hope for a cure for leukemia.

In recent years, it has been gradually revealed that a series of signaling pathways, such as Wnt, Notch, the TGF- $\beta$ family, Hedgehog and Hippo signaling, could affect the stemness of HSCs, and that dysregulations of these pathways alone or coordinated may lead to the development of leukemia $(7,8)$. Among them, Notch signaling, an evolutionarily conserved signaling pathway, is essential for the establishment of the earliest embryonic HSCs and is closely associated with the emergence, development, and maintenance of HSCs in adulthood (9). In this signaling pathway, Notch1 receptor is most closely associated with the stemness of HSCs and plays a key role in T-cell development and transformation (10). Abnormally activated or mutated Notch1 receptors severely affect the balance of proliferation and differentiation of HSCs which triggers the continuous emergence of abnormal lymphocytes, thus leading to lymphocytic leukemia, particularly T-cell acute lymphoblastic leukemia (T-ALL). In addition to the Notch1 receptor itself, its post-translational modifications, such as glycosylation, phosphorylation, and ubiquitination, also affect the activation of the Notch1 pathway, thereby affecting the stemness of HSCs (11). Among these post-transcriptional modifications, particular attention has been paid to the ubiquitination modification of Notch1, since it affects the degradation of Notch1 receptor (12), the activation of Notch1 signaling (11), and the process of endocytosis that Notch1 receptor undergoes (13). Therefore, this suggests that the key enzymes responsible for the ubiquitination modification of Notch1 may also, directly or indirectly, affect the stemness of HSCs and the development of leukemia (14-16). In the present review, the structure of the Notch signaling pathway was firstly summarized in detail and the effects of the Notch1 receptor on HSC origin, proliferation, differentiation and associated T-ALL, were described. Subsequently, the ubiquitination modification of Notch1 receptor and its effects on HSCs were elucidated. Finally, the clinical application of HSCs, as well as the potential therapeutic targets and prognostic indicators of Notch were reviewed.

\section{Overview of the Notch pathway}

Notch signaling is a major mediator in determining cell fate during development, and it regulates a variety of cell functions, including differentiation, proliferation, and homeostasis (17). Evidence suggests that the Notch signaling pathway has markedly opposite functions in tumor development, possibly acting as an oncogene or a tumor suppressor (18). In the process of hematopoiesis, Notch signaling controls the fate of hematopoietic progenitor stem cells by inhibiting certain differentiation steps and inducing self-renewal or lymphatic lineage differentiation (19).

Notch receptor, Notch ligand and DNA binding sequence $\mathrm{CSL}[\mathrm{CBF} 1 / \mathrm{SU}(\mathrm{H}) / \mathrm{LAG}-1]$ are the three main components of the canonical Notch signaling pathway (20). There are four transmembrane Notch receptors (Notch1, Notch2, Notch3, and Notch4) and five typical transmembrane ligands [Delta-like (DLL) 1, DLL 3, DLL 4, Jagged1, and Jagged 2] in mammals (21). The extracellular region of the Notch receptor (NECD) contains 29-36 epidermal growth factor (EGF)-like repeats, three LIN12/Notch repeats and a heterodimerization (HD) domain. Notch intracellular domains (NICD) include a RAM domain, seven cdc10/ankyrin repeats, two nuclear localization sequences, a transactivation domain (TAD) (Notch1 and Notch2), and a C-terminal PEST motif (22) (Fig. 1A). Notch ligand is a type I transmembrane protein that contains extracellular EGF-like repeats, a Delta, Serrate and LAG-2 domain and a Delta and OSM-11-like protein domain, which together are responsible for Notch receptor interactions (21).

The Notch signaling pathway is activated when a ligand on a cell membrane binds to the Notch receptor on an adjacent cell. The Notch receptor passes through three different proteolytic cleavages (Fig. 1A). First, a single polypeptide precursor protein is cleaved in the Golgi by a furin-like convertase to produce a mature Notch receptor (S1) (21). When the mature Notch receptor binds to the ligand, a second cleavage (S2) is performed by TACE or Kuz of the A disintegrin and metalloprotease metalloproteinase family to release extracellular fragments (20). The remaining transmembrane and intracellular domains are cleaved by $\gamma$-secretase for a third time (S3), releasing the soluble NICD and transferring to the nucleus (20). Then, NICD binds to the DNA-binding protein CSL/RBPJ $\kappa$ in the nucleus, activating genes which belong to the basic helix-loop-helix (bHLH) family (20). The general consensus is that $\mathrm{CSL} / \mathrm{RBPJ} \kappa$ persistently binds to the promoter of the targeted gene. In the absence of NICD, CSL/RBPJ $\kappa$ binds with co-inhibitors (SMRT, histone deacetylase, etc.) to inhibit gene transcription. Conversely, when NICD enters the nucleus, it recruits co-activators such as MAML to promote the transcription of target genes (23). In mammals, genes known as the Hes family $(H e s 1,5,7)$ and the Hey family $(H e y 1,2, L)$ are the major components of the $b H L H$ family (24-26). Hesl is important in the development of the nervous system, sensory organs (eye, inner ear), pancreas, endocrine cells, and lymphocytes (24). Hes 7 is essential for somitogenesis (25). By contrast, the Hey family play a key role in the cardiovascular system (26). In addition to the $b H L H$ family, several other genes have also 

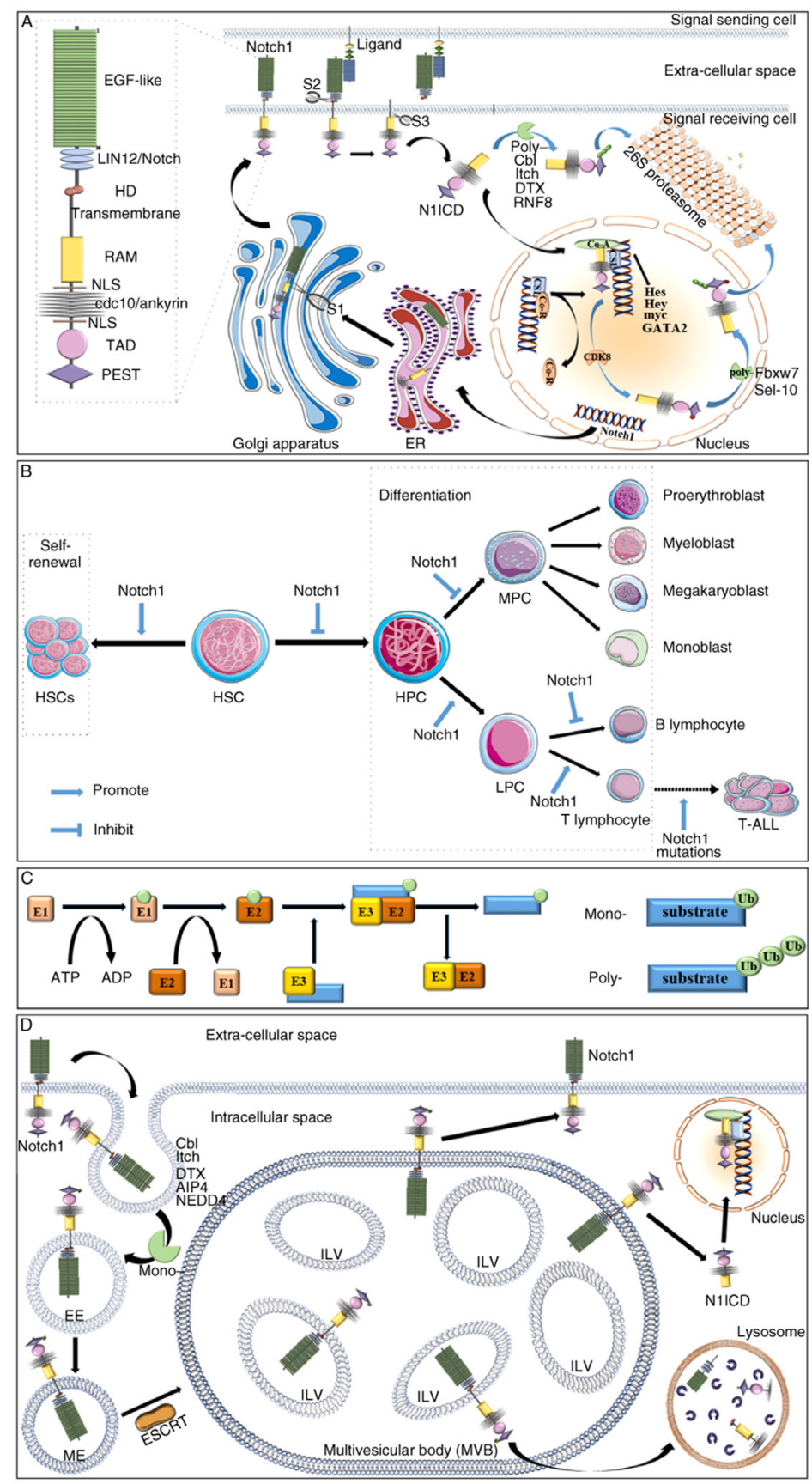

Figure 1. Notch1 and HSCs. (A) Notch1 receptor structure and Notch1 signaling. Notch1 receptors are composed of an intracellular domain (36 EGF-like repeats, three LIN12/Notch repeats and an HD domain), a transmembrane domain and an extracellular domain (RAM domain, seven cdc10/ankyrin repeats, two NLS, a TAD domain, and a PEST motif). The Notch1 receptor undergoes three proteolysis processes to become N1ICD. Above all, the precursor Notch1 receptor is cleaved by a furan-like convertase (S1) in the Golgi apparatus. When bound to the ligand, TACE or Kuz perform a second cleavage (S2). The remaining domain is cleaved by $\gamma$-secretase (S3) to release N1ICD. The N1ICD enters the nucleus and the target gene is detached from the Co-R. Then, N1ICD, together with SCL and Co-A, promotes the transcription of target genes. N1ICD in the nucleus and cytoplasm is degraded by $26 \mathrm{~S}$ proteasome through a process of poly-ubiquitination modification. However, N1ICD in the nucleus is phosphorylated by CDK8 before the ubiquitination modification. (B) Effects of Notch1 signaling on self-renewal (proliferation) and differentiation of HSCs. In general, Notch1 promotes the proliferation of HSCs and inhibits their differentiation. However, when hematopoietic stem cells begin to differentiate, Notch1 promotes hematopoietic stem cells to differentiate into T lymphocyte lines rather than myeloid lines. In addition, Notch1 signaling drives T-cell development at the expense of the development of B cells. In the end, the most important carcinogenic pathway in T-ALL is the activation mutation of Notch1 signaling. (C) Processes and types of ubiquitination modification. The ubiquitin molecule is added to the substrate by the action of E1,E2 and E3 in turn. Ubiquitination modification mainly involves mono-ubiquitination modification and poly-ubiquitination modification.(D) The process of endocytosis. When no ligand binds, Notch1 undergoes endocytosis. Notch1 is mono-ubiquitinated before EE is formed. Then, EE will gradually mature into ME. Subsequently, the multiple MEs are fused into MVEs with the assistance of ESCRT. The position of Notch1 on the MEVs determines its fate. If Notch1 is present on the limiting membrane of MVBs, it may be recycled to the cell membrane for utilization. If Notch1 on the MVB-limiting membrane is cleaved and N1ICD is released, Notch1 signaling will be activated. However, the residual Notch1 in ILVs is transported to lysosomes for degradation. EGF-like, 36 epidermal growth factor (EGF)-like repeats; LIN12/Notch1, three LIN12/Notch repeats; HD, heterodimerization domain; transmembrane, transmembrane domain; RAM, RAM domain; NLS, nuclear localization sequences; cdc10/ankyrin, seven cdc10/ankyrin repeats; TAD, transactivation domain; PEST, PEST motif; ER, endoplasmic reticulum; S1, first proteolytic cleavage; S2, second proteolytic cleavage; S3, third proteolytic cleavage; N1ICD, Notch1 intracellular domains; Co-A, co-activators; Co-R, co-inhibitors; CSL, DNA-binding protein CSL/RBPJ ; HSC, hematopoietic stem cell; HPC, hematopoietic progenitor cell; MPC, myeloid progenitor cell; LPC, lymphoid progenitor cell; T-ALL, T-cell acute lymphoblastic leukemia; E1, ubiquitin-activating enzyme; E2, ubiquitin-conjugating enzyme; E3, ubiquitin ligase; mono-, mono-ubiquitination; poly-, poly-ubiquitination; Ub, ubiquitin molecule; EE, early endosome; ME, maturing endosome; ESCRT, endosomal sorting complexes required for transport; ILV, interluminal vesicle. 
been identified as Notch targets, including $p 27^{\text {Kipl }}(27)$ cyclin Dl (28), myc (29), and Deltexl (30).

The main substrates that undergo ubiquitination modification in this signaling pathway are Notch receptor, Notch ligand and $\gamma$-secretase (31). Among them, the ubiquitination modification of Notch receptor, particularly Notch1 receptor, may mostly affect the signaling strength of this pathway (31). The Notch1 receptor firstly undergoes either mono-ubiquitination or poly-ubiquitination, thereafter the Notch1 receptor is degraded or the Notch1 signaling is activated, thereby affecting the Notch1 signaling and the expression of downstream genes. The detailed process is subsequently described.

Since Notch1 receptor-mediated Notch1 signaling plays an irreplaceable role in the blood system, The Cancer Genome Atlas database (https://portal.gdc.cancer. gov/exploration?filters $=\% 7 \mathrm{~B} \% 22 \mathrm{op} \% 22 \% 3 \mathrm{~A} \% 22 \mathrm{and} \% 22 \% 2 \mathrm{C}$ $\% 22$ content $\% 22 \% 3 \mathrm{~A} \% 5 \mathrm{~B} \% 7 \mathrm{~B} \% 22 \mathrm{op} \% 22 \% 3 \mathrm{~A} \% 22 \mathrm{in} \% 22 \%$ $2 \mathrm{C} \% 22$ content $\% 22 \% 3 \mathrm{~A} \% 7 \mathrm{~B} \% 22$ field $\% 22 \% 3 \mathrm{~A} \% 22$ cases. available_variation_ta\%22\%2C $\% 22$ value $\% 22 \% 3 \mathrm{~A} \% 5 \mathrm{~B} \% 22 \mathrm{ss}$ m\%22\%2C\%22cnv\%22\%5D \%7D\%7D\%2C\%7B\%22op\%22\% $3 \mathrm{~A} \% 22 \mathrm{in} \% 22 \% 2 \mathrm{C} \% 22$ content $\% 22 \% 3 \mathrm{~A} \% 7 \mathrm{~B} \% 22$ field $\% 22 \% 3 \mathrm{~A}$ $\% 22$ cases.project.project_id $\% 22 \% 2 \mathrm{C} \% 22$ value $\% 22 \% 3 \mathrm{~A} \% 5 \mathrm{~B}$ $\% 22$ TARGET-ALL-P3\%22\%2C\%22TCGA-DLBC $\% 22 \% 2 \mathrm{C} \%$ 22TCGA-LAML $\% 22 \% 5 \mathrm{D} \% 7 \mathrm{D} \% 7 \mathrm{D} \% 2 \mathrm{C} \% 7 \mathrm{~B} \% 22 \mathrm{op} \% 22 \% 3$ A $\% 22$ in $\% 22 \% 2 \mathrm{C} \% 22$ content $\% 22 \% 3 \mathrm{~A} \% 7 \mathrm{~B} \% 22$ field $\% 22 \% 3 \mathrm{~A}$ $\% 22$ genes.gene_id $\% 22 \% 2 \mathrm{C} \% 22$ value $\% 22 \% 3 \mathrm{~A} \% 5 \mathrm{~B} \% 22 \mathrm{ENS}$ G00000148400\%22\%5D\%7D\%7D\%5D\%7D\&searchTableTa $\mathrm{b}=$ cases) and the International Cancer Genome Consortium database (https://dcc.icgc.org/genes/ENSG00000148400/ mutations?donors $=\% 7 \mathrm{~B} \% 22$ from $\% 22: 1 \% 7 \mathrm{D} \&$ filters $=\% 7 \mathrm{~B} \%$ 22donor\%22:\%7B\%22primarySite\%22:\%7B\%22is\%22:\%5B \%22Blood\%22\%5D\%7D\%7D\%7D) were consulted, respectively, and data on the expression and mutations of Notchl were obtained by searching for Notchl mutations and selecting all hematology-related malignancies in the database, including various types of lymphomas and leukemias. The Notch1 mutation rate was 32/241 (13.28\%) in germinal B-cell derived lymphomas, 64/510 (12.55\%) in CLL, 3/50 (6.00\%) in T- and NK-cell lymphomas, 11/205 (5.37\%) in AML and $1 / 136(0.74 \%)$ in chronic myeloid disorders. Through further integrating these data into disease categories, it was identified that Notchl was mutated with a frequency of $9.72 \%$ in hematological malignancies. Furthermore, the mutation frequency of Notchl in lymphomas was 12.03 and $8.93 \%$ in leukemias.

\section{Notch1 and HSCs}

Origin of HSCs. HSCs are the cornerstone of the mammalian blood system (32). These stem cells self-renew to maintain a stable pool of HSCs, which are able to differentiate into myeloid, lymphatic and erythroid cells as required, thus maintaining blood cell homeostasis (32). The Notch signaling pathway, particularly the Notch1 receptor, plays a key role in maintaining undifferentiated HSCs and inducing self-renewal (9). Thus, Notch1 is biologically important in HSCs.

During human embryonic development, two distinct sites are involved in hematopoiesis: The extraembryonic yolk sac (YS) and the aorta-gonadal-mesonephric (AGM) region within the embryo (33). The hematopoiesis starts in the YS blood islands, travels to the fetal liver, and finally locates to the bone marrow during embryogenesis. Additionally, adult blood cells, including lymphocytes and hematopoietic progenitor cells (HPCs), are generated in the para-aortic splanchnopleure (P-SP) region, which then develops into AGM for long-term hematopoiesis before the HSCs reach the fetal liver (34). The first long-term regenerated HSCs are detected in the AGM region. By positively regulating Notch1 through the transcription factor SOX17, Saito et al (35) revealed that Notch1 intracellular domain (N1ICD) or its downstream target protein Hes1 transduced HSCs to maintain the ability of multipotent colony formation in AGM. By contrast, Notchl and Hes 1 gene knockout resulted in a decrease in the ability to form multipotent colonies. These results indicate that Notch1 and Hes1 are critical for maintaining the undifferentiated state of HSCs (35). Thus, Notch1 is critical to the production of HSCs during embryogenesis.

With regard to the origin of HSCs, it is generally considered that embryonic HSCs and progenitor cells are derived from the hematopoietic endothelium, and thus the transformation of hematopoietic endothelial cells into HSCs and progenitor cells (EHT) is required.Zhang et al (36) demonstrated that inhibition of Notch1 signaling can promote EHT by G protein-coupled receptor 183. In mouse embryos with Notchl deletion mutations, distinct hematopoietic endothelial cells were identified, but they did not develop into HSCs (37). Differences in the ligands that activate Notch1 may contribute to the paradoxical nature of the results. Through analysis of experimental data, Gama-Norton et al (38) revealed that $89 \%$ of endothelial cells co-expressed Jagged1 and DLL4 ligands, and only a few endothelial cells expressed Jagged1 ligands alone (3.8\%) or DLL4 ligands alone $(4.6 \%)$ or neither $(2.5 \%)$. The balance of the DLL4-Notch1 and Jagged1-Notch1 signaling pathways may ensure the correct establishment of endothelial and hematopoietic cell fates in AGM. Furthermore, they suggested that the deletion of Jagged1 ligand leads to increased Notch activity in the aortic endothelium of AGM through the microarray analysis of AGM subpopulations, thereby improving the fate of endothelial cells at the expense of HSC formation. Conversely, when lacking the Jagged1-Notch1 signaling and experiencing high DLL4-Notch1 signaling, endothelial cells select the endothelial protocol, thus preventing the formation of HSCs. It was hypothesized that precursor hematopoietic cells responding to Jagged1 would attenuate the DLL4-Notch1 signaling, replacing it with an effective low Notch1 signaling, which is necessary and sufficient for activation of hematopoietic genes such as GATA2 (38). In addition to GATA2, Fox2 from the Fox gene family induced by N1ICD also plays a role in hematopoietic endothelium. Data from a study by Jang et al (39) established a pathway that binds Notch signaling to its downstream Fox2 in hematopoietic endothelial cells, thereby promoting hematopoietic development. Collectively, these studies suggested that Notch1 has an indispensable role prior to HSC production (37).

Proliferation and differentiation of HSCs. Through downstream proteins or genes, particularly Hes1, the Notch signaling pathway mediated by Notch1 receptor promotes self-renewal of HSCs and inhibits their differentiation (Fig. 1B). Using Rag-1-1mouse stem cells, Stier et al (40) documented Notch1-induced reduction of in vivo differentiation and an increased stem cell 
population due to enhanced stem cell self-renewal. The research of Shao et al (41) revealed that endothelial Jagged1-Notch1 deficiency severely affects the development of fetal blood vessels and impedes the proliferation and differentiation of HSCs in vitro and in vivo. Additionally, it was specified that Notch1-Hes1 may act on hematopoietic precursor cells, which are produced following the fate of HSCs. Furthermore, Hes1 not only preserved the long-term recombination activity of HSCs in vitro, but also accumulated side population cells in vivo (42). These results suggested that Hes1 inhibits HSC differentiation. However, once HSCs enter the differentiation stage, Notch1 signaling promotes HSC differentiation, with a preference for the lymphatic rather than the myeloid line (40) (Fig. 1B). A previous study conducted by Henning et al (43) suggested that Notch1 signaling mediates this process via a p53-dependent pathway. Collectively, the main effect of Notch1 signaling on HSCs is to promote its proliferation and inhibit its differentiation.

HSCs differentiate into T cells. When HSCs first enter the thymus and become early T-cell precursor (ETP) cells, they receive high levels of Notch signaling regulation (44). On the one hand, excessive Notch1 signaling drives premature commitment of T cells, leading to loss of ETP cells and the fate of replacement cells (44). By contrast, complete loss of Notch1 signaling impairs ETP cell proliferation and leads to loss of ETP cells (44). Thus, maintaining a good balance of Notch signaling can maintain the stemness of HSCs.

In both mouse and human, Notch1 activation is the primary driver of inducing T-cell development in hematopoietic stem progenitor cells (Fig. 1B). The role of Notch1 in lymphogenesis has been well studied, and in particular the most prominent characteristic function of Notch1 signaling is maturation of $\mathrm{T}$ cells and lineage commitment in the mouse thymus (45). It has been demonstrated that the expression of Notchl transgene in HSCs leads to thymus-independent development of $\mathrm{CD} 4^{+} \mathrm{CD} 8^{+} \mathrm{T}$ cells (45). In addition, the study of Gerhardt et al (46) revealed that TAD in Notch1 drives T-cell development at the expense of common precursor development of B cells.

Notably, downstream target genes of Notch1, such as Hes and $m y c$, are the driving force in the differentiation of HSCs into T cells. Hes 1 has been revealed to be expressed in both the thymus and thymus stroma, and its expression in the thymus was regulated by Notch signaling (47). More than $90 \%$ of $\mathrm{Hes}^{-1}$ mice lacked thymus glands, suggesting that Hesl is critical for the in vivo proliferation of early T-cell precursors (48). In a recent study, De Decker et al (49) identified that Hes1 and Hes4 were upregulated in a Notch-dependent manner during early T-cell development and Hes1 acted as a differentiation inhibitor since it maintained quiescent stem cell characteristics in CD $34^{+}$HPCs. However, Hes 4 promoted the initiation of early T-cell development. Importantly, knockout of Hes 1 or Hes 4 significantly reduced human T-cell development. As for $m y c$, in a well-established model of HSC T-lymphocyte differentiation in vitro, Haque et al (50) determined that Notch1 and 4 directly promoted myc expression. It was further demonstrated that overexpression of myc promoted T-cell differentiation, while dominant-negative myc delayed T-cell differentiation. These results confirmed that $m y c$ is an important mediator of Notch signaling in the differentiation of HSCs into T lymphocytes. The Notch1-mediated emergence of these two different effects on HSC differentiation into T cells may be attributed to the Notch ligand. OP9-cell co-culture experiments revealed that Jagged 2 induced T-line differentiation and inhibited B cell and bone marrow development, as did DLL ligands (51). However, the results of Van de Walle et al (51) revealed a unique role of Jagged1 in preventing induction of differentiation of HSCs in T lines.

T-ALL. T-ALL is an aggressive hematologic tumor in which the malignant transformation of HSCs and HPCs lead to the development of T cells (52). Although T-ALL accounts for only $25 \%$ of ALL cases in adults and $15 \%$ in children, they have a higher risk of central nervous system recurrence in the presence of mutations activated by the Notch1 signaling pathway (53). Constitutive activation of Notch1 signaling is the most important oncogenic pathway in T-cell transformation, and $>65 \%$ of T-ALL patients have Notchl activation mutations (52). In addition, Ma et al (53) concluded that Notch1 signaling promotes cell regeneration in human T-ALL. Most of the abnormal activation of Notch1 observed in T-ALL is due to mutations in its HD domain and/or PEST domain (54). Of the 15 T-ALL patients studied by Bhanushali et al (54), 6 (40\%) patients had at least one Notchl mutation, with 2/15 (13\%) occurring in the HD domain and 4/15 (27\%) in the PEST domain. In addition, mutations are considered to occur in 4 out of $10(40 \%)$ adult patients; in the pediatric cohort, two out of five (40\%) had both mutations in the PEST domain (54). Mutations in the HD domain of Notch1 receptor render it more susceptible to protein cleavage and then release of N1ICD, while mutations in the PEST domain of Notch1 receptor inhibit proteasomal degradation of N1ICD by F-box and WD repeat domain containing 7 (Fbxw7), which is a ubiquitin ligase, thus prolonging its half-life in T-All cells. In addition, deletion or inactivation mutations of $F b x w 7$ are frequently observed in T-ALL. In addition, Ding et al (55) revealed that fetal-derived T-cell precursor stem cells may play a role as leukemia initiation cells. This may be due to their discovery of overexpression of N1ICD in P-SP and YS cells. P-SP cells overexpressing N1ICD rapidly developed T-ALL, while YS cells exhibited no leukemia proliferation following N1ICD induction. To date, Notchl mutations have also been reported in CLL (56). Di Ianni et al (56) reported Notchl mutation in HSCs of CLL patients, and aberrant activation of Notch1 in HSCs of CLL patients without Notch1 mutation.

\section{Notch1 and ubiquitination}

Ubiquitination. Ubiquitination is a common and important post-translational modification process that plays a key role in protein homeostasis (57). It is mainly achieved through labeling the ubiquitin (an $8.6 \mathrm{kDa}$ regulatory protein) to the substrate, which is then degraded in the $26 \mathrm{~S}$ proteasome to release the ubiquitin molecule (58). In addition, ubiquitination also includes certain non-proteolytic functions, such as receptor internalization (59), multiprotein complex assembly (60), inflammatory signaling (61), DNA damage repair (62), cell death (63), metabolism (64) and signaling activation $(65,66)$. 
Ubiquitination involves three different biochemical steps: activation, conjugation, and ligation, which are catalyzed by three types of ubiquitination enzymes: Ubiquitin-activating enzyme (E1), ubiquitin-conjugating enzyme (E2), and ubiquitin ligase (E3), respectively (67) (Fig. 1C). Initially, E1 causes the C-terminal adenylation of ubiquitin ( $\mathrm{Ub}$ ) to catalyze the activation of ubiquitin in an ATP-dependent manner (68). The mature ubiquitin is then transferred to cysteine at the active site of the E2 binding enzyme via trans-thiesterification (58). Finally, E3 and E2 jointly catalyze the formation of isopeptide bonds between $\mathrm{Ub}$ and the substrate protein (69). Once attached to the target protein, ubiquitin can be ubiquitinated on any of its lysine residues (K6, K11, K27, K29, K33, K48, K63) or on its N-terminal methionine (M1). The human proteome contains two E1s, 50 E2s, and 600 E3s (70). Since largely determining substrate specificity, E3 plays a key role in the entire process of ubiquitination modification. E3s could be roughly divided into three families: the HECT family, the RING family, and the RBR family (64).

The E1-E2-E3 cascade is capable of producing several types of $\mathrm{Ub}$ modifications, resulting in the different fates of substrates (3). In general, two types of ubiquitination modification are prevalent in cells: Mono-ubiquitination and poly-ubiquitination (Fig. 1C). On the one hand, mono-ubiquitination is the addition of a single $\mathrm{Ub}$ molecule to the substrate. Poly-ubiquitination, by contrast, is the addition of Ub chains to one or more lysine residues of the substrate (3). In most cases, membrane-bound proteins are mono-ubiquitinated, which contributes to their endocytosis and lysosomal degradation $(31,71)$. In addition, mono-ubiquitination is also involved in meiosis and chromatin remodeling. However, poly-ubiquitination plays a role in the ubiquitin-proteasome system (UPS), DNA repair, and immune signaling transduction (72).

Ubiquitination modification of Notchl receptor. Recent studies have suggested that the ubiquitination modification of Notch1 receptor plays an irreplaceable role in the regulation of Notch signaling (73-81). The ubiquitinated Notch1 receptor has three distinct fates: Transferring to the $26 \mathrm{~S}$ proteasome, promoting N1ICD-mediated signaling activation, and the endocytosis of Notch1 receptor. The fate of the Notch1 receptor that transfers to the $26 \mathrm{~S}$ proteasome is degradation. However, the entry of Notch1 receptors into the process of endocytosis has three different outcomes: Cycling back to the cell membrane, becoming N1ICD and functioning in the nucleus or being degraded in lysosomes.

Above all, the most important function of ubiquitinated Notch1 is degradation in the $26 \mathrm{~S}$ proteasome (Fig. 1A). The E3s that mediate this process are mainly Sel-10, Fbxw7 and RNF8. When N1ICD enters the nucleus, it forms complexes with MAML and CSL. Among them, MAML can recruit CDK8 to phosphorylate the PEST domain of N1ICD. Subsequently, Fbxw7, an E3, modifies the phosphorylated N1ICD for poly-ubiquitination and then enters into the $26 \mathrm{~S}$ proteasome for degradation (12). Similarly, Wu et al (82) demonstrated that human Sel-10 (hSel-10) and Sel-10 bind N1ICD proteins in a region-specific manner and that the interaction between Sel-10 and N1ICD is phosphorylation-dependent. In vitro ubiquitination modification experiments also revealed that Sel-10 and hSel-10 mediated ubiquitination modification of N1ICD, which were subsequently degraded by the $26 \mathrm{~S}$ proteasome in cells. As for RNF8, it acts as a negative regulator of Notch signaling through ubiquitination modification of N1ICD, leading to its degradation, thereby regulating Notch1 signaling and cell fate determination in lumen progenitor cells of the breast (83).

Another essential role of the ubiquitination modification of Notch1 is the activation of Notch signaling. Pettersson et al (11) revealed that MDM2 also regulates Notch signaling through direct interaction with N1ICD, leading to ubiquitination modification of N1ICD. However, this type of ubiquitination modification does not result in the degradation of N1ICD, but triggers the activation of the Notch signaling pathway. In addition, MDM2 also interacts with Notch regulator NUMB and induces its ubiquitination modification and degradation (11).

With the exception of the Notch1 proteasomal degradation and signaling activation, ubiquitination modification also regulates the endocytosis of Notch1 (Fig. 1D). In the absence of a ligand, Notch1 is continuously internalized and then degraded in lysosomes (84), circulating back to the plasma membrane $(85,86)$ or activating Notch signaling. This mechanism is a way to maintain Notch1 function and ultimately regulate Notch signaling strength by targeting Notch1 levels on the cell surface. Notch1 begins the process by its internalization in the early endosome (EE) vesicles and then fuses with the EE. The EE then matures and merges into a maturing endosome (ME). Finally, multiple MEs fuse to form multivesicular bodies (MVBs). In this step, Notch1 has the three distinct aforementioned fates, specifically, it either returns to the membrane by circulating endosomes, remains in MVBs, or activates the Notch1 signaling. These different fates depend on the position of Notch1 in MVBs. If Notch1 is present on the limiting membrane of MVBs, it can be recycled, and when the part of Notch1 present on the MVB-limiting membrane is cleaved to release N1ICD, Notch1 signaling can be activated (31). However, Notch1 remaining in MVB interluminal vesicles (ILVs) can be further degraded by lysosomes. MVB formation is controlled by endosomal sorting complexes required for transport (ESCRT), a sequentially acting macromolecular protein complex that ultimately allows ILV formation $(87,88)$. Mono-ubiquitination modification of Notch1 has been revealed to be necessary for effective recruitment to the endosomal membrane by the ESCRT machinery components and formation of ILV (89). If the ESCRT mechanical component is not functional, the mono-ubiquitinated Notch1 accumulates on the limiting membrane of MVBs, resulting in aberrant signaling activation. This suggests that mono-ubiquitination modification may be directly or indirectly involved in Notch endocytosis regulation and vesicular transport. The E3s that mediate this process include $\mathrm{Su}(\mathrm{dx}) / \mathrm{Itch} / \mathrm{AIP} 4, \mathrm{Cbl}$, NEDD4, and Deltex (DTX). The results of their effects depend on the cell contexts, as well as their abundance. In addition, $\mathrm{Su}(\mathrm{dx}) / \mathrm{Itch} / \mathrm{AIP} 4, \mathrm{DTX}$, and NEDD4 may also enable Notch1 to be labeled by poly-ubiquitination modification and then degraded into proteasome (73-81) (Table I).

Effects on HSCs. Regulation of N1ICD through ubiquitination modification is absolutely critical for proper Notch signaling, as maintaining Notch signaling over long periods of time can lead to severe diseases. For example, either a deletion of the Notchl gene, leading to a deletion of the PEST domain of 
Table I. E3s of Notch1 receptor.

\begin{tabular}{|c|c|c|c|c|c|c|}
\hline E3 & Substrate & Species & E3-type & Ubiquitination & Effect & (Refs.) \\
\hline Sel-10 & N1ICD & $\begin{array}{l}\text { Caenorhabditis } \\
\text { elegans }\end{array}$ & RING & poly- & Proteasome degradation & (73) \\
\hline hSel-10 & N1ICD & Human & RING & poly- & Proteasome degradation & $(82)$ \\
\hline Fbxw7 & N1ICD & Mammal & RING & poly- & Proteasome degradation & (12) \\
\hline RNF8 & N1ICD & Mammal & RING & poly- & Proteasome degradation & (83) \\
\hline MDM2 & N1ICD & Mammal & RING & mono- & Signaling activation & (11) \\
\hline $\mathrm{Su}(\mathrm{dx})$ & Notch1 & Drosophila & HECT & $\begin{array}{l}\text { mono- } \\
\text { poly- }\end{array}$ & $\begin{array}{l}\text { Endocytosis } \\
\text { Proteasome degradation }\end{array}$ & $(74,75)$ \\
\hline Itch & Notch1 & Mammal & HECT & $\begin{array}{l}\text { mono- } \\
\text { poly- }\end{array}$ & $\begin{array}{l}\text { Endocytosis } \\
\text { Proteasome degradation }\end{array}$ & $(76,77)$ \\
\hline AIP4 & Notch1 & Human & HECT & $\begin{array}{l}\text { mono- } \\
\text { poly- }\end{array}$ & $\begin{array}{l}\text { Endocytosis } \\
\text { Proteasome degradation }\end{array}$ & $(85)$ \\
\hline NEDD4 & Notch1 & $\begin{array}{l}\text { Drosophila, } \\
\text { mammal }\end{array}$ & HECT & $\begin{array}{l}\text { mono- } \\
\text { poly- }\end{array}$ & $\begin{array}{l}\text { Endocytosis } \\
\text { Proteasome degradation }\end{array}$ & $(77,78)$ \\
\hline DTX & Notch1 & $\begin{array}{l}\text { Melanogaster, } \\
\text { mammal }\end{array}$ & RING & mono- & $\begin{array}{l}\text { Endocytosis } \\
\text { (upgrade signaling) }\end{array}$ & $(13,79,80)$ \\
\hline $\mathrm{Cbl}$ & Notch1 & Vertebrate & RING & $\begin{array}{l}\text { poly- } \\
\text { mono- } \\
\text { poly- }\end{array}$ & $\begin{array}{l}\text { Proteasome degradation } \\
\text { Lysosomal degradation } \\
\text { Proteasome degradation }\end{array}$ & $(16,81)$ \\
\hline
\end{tabular}

N1ICD, Notch1 intracellular domains; E3, ubiquitin ligase; DTX, Deltex.

Notch, or a mutation in the $F b x w 7$ gene, encoding an inactive or absent enzyme is associated with T-ALL (88). In the present study, three E3s were focused on, all of which affect the stemness of HSCs through Notch1 receptor.

Cell cycle quiescence maintains the stemness of HSCs by protecting them from differentiation or senescence (90). Fbxw7 can induce the degradation of positive regulators such as myc and Notch1 in the cell cycle. Iriuchishima et al (91) revealed that Fbxw7 maintained HSCs and inhibited leukemia by mediating ubiquitin-dependent degradation of myc and Notch1. Thompson et al (92) also demonstrated that the Fbxw $7^{-/-}$severely affected the maintenance of HPCs in the bone marrow, and the cell autonomy defect of stem cell self-renewal led to the defect of HSC silencing and self-renewal, which was attributed to the loss of the function of $\mathrm{Fbxw} 7$ deletion to ubiquitination modification and degradation of Notch1 or myc. Therefore, Fbxw7 serves as a key fail-safe device to prevent premature loss of HSCs and the development of T-ALL (93).

In addition, $\mathrm{Cbl}$ is a new negative regulator of HSC development and functional characteristics. Rathinam et al (94) determined that HSCs of $\mathrm{Cbl}^{-/-}$mice had increased pool capacity, increased proliferation, and increased long-term regeneration. Furthermore, Zhu et al (16) revealed that flavone promoted Cbl-induced ubiquitination modification and degradation of N1ICD, resulting in resistance to T-ALL.

Ultimately, HSCs in $\mathrm{Itch}^{-/-}$mice exhibited increased frequency, ability, and long-term regenerative activity. Rathinam et al (95) demonstrated that Itch-deficient HSCs exhibited accelerated proliferation rates and sustained progenitor cell properties due to increased accumulation of Notch1 activation, as well as increased Notch1 signaling by the transcription factor. Therefore, E3 ubiquitin ligase Itch negatively regulates the development and function of HSCs.

\section{Clinical application}

Multipotent stem cells, particularly HSCs and MSCs, are widely used in clinical practice due to their characteristics of self-renewal, multidirectional differentiation as well as numerous others. For example, MSCs have paracrine, anti-inflammatory, and immunomodulatory effects in addition to their role in tissue regeneration (96). MSC-derived chambers or substances (including exosomes, microvesicles, and microRNA) can serve as practical tools for diagnosing, following up, managing, and monitoring disease. In addition, Tehrani et al (97) suggested that MSCs could serve as a vehicle for gene-directed enzyme prodrug therapy, in which suicide genes are directed to tumor cells, attributing to their remarkable homing properties to the tumor sites. Mirzaei et al (98) considered that MSCs could carry 5-fluorouracil, suicide genes such as pigment epithelium-derived factor, INF- $\alpha, I N F-\beta$ and $I N F-\gamma$ to melanoma sites to inhibit tumor growth. More specifically, interferon- $\gamma$-induced protein $10 \mathrm{kDa}$ (IP-10) secreted by human adipose-derived MSCs may be involved in this process (99). In addition, it has been gradually determined that this method of gene therapy can also be applied to the treatment of osteoarthritis (100), cardiovascular disease (101) as well as other diseases, in recent years. However, MSCs also secrete certain growth factors, chemokines, and cytokines, which increase the burden of tumors, and this may be the most important unresolved issue with this treatment approach (102). 
Table II. HSCT.

\begin{tabular}{|c|c|c|c|c|c|c|}
\hline Type & $\begin{array}{l}\text { Recurrence } \\
\text { rate at } \\
100 \text { days } \\
\text { following } \\
\text { HSCT }\end{array}$ & $\begin{array}{c}\text { 5-Year } \\
\text { survival } \\
\text { rate }\end{array}$ & $\begin{array}{l}\text { Main risk } \\
\text { factor } \\
\text { for late } \\
\text { mortality }\end{array}$ & $\begin{array}{l}\text { Indications } \\
\text { for } \\
\text { malignant } \\
\text { tumors }\end{array}$ & $\begin{array}{c}\text { Indications } \\
\text { for other } \\
\text { diseases }\end{array}$ & (Refs.) \\
\hline Auto-HSCT & $57 \%$ & $88 \%$ & Relapse & $\begin{array}{l}\text { MM, NHL, HL, } \\
\text { AML, ALL, } \\
\text { neuroblastoma, } \\
\text { ovarian } \\
\text { cancer, germ-cell } \\
\text { tumors, etc. }\end{array}$ & $\begin{array}{l}\text { Autoimmune } \\
\text { disorders, } \\
\text { amyloidosis, } \\
\text { etc. }\end{array}$ & (106-109) \\
\hline Allo-HSCT & $46 \%$ & $83 \%$ & $\begin{array}{l}\text { Chronic } \\
\text { GVHD }\end{array}$ & $\begin{array}{l}\text { AML, ALL, CML } \\
\text { NHL, HL, CLL, } \\
\text { MM, MDS, } \\
\text { myeloproliferative } \\
\text { disorders, etc. }\end{array}$ & $\begin{array}{l}\text { AA, PNH, } \\
\text { Fanconi's anemia, } \\
\text { sickle cell anemia, } \\
\text { Wiskott-Aldrich } \\
\text { syndrome, etc. }\end{array}$ & $(107,108,110)$ \\
\hline
\end{tabular}

HSCT, hematopoietic stem cell transplantation; MM, multiple myeloma; MDS, myeloproliferative disorders; NHL, non-Hodgkin's lymphoma; HL, Hodgkin's lymphoma; ALL, acute lymphoblastic leukemia; CLL, chronic lymphocytic leukemia; AML, acute myelogenous leukemia; CML, chronic myelogenous leukemia; AA, aplastic anemia; PNH, paroxysmal nocturnal hemoglobinuria.

Since the Notch1 signaling pathway and its UPS mainly affect the stemness of HSCs, attention should be paid to the progression of HSCs in the treatment of leukemia, so as to provide a better direction for the treatment of leukemia. HSC-related therapies are gradually applied in the treatment of leukemia. Transplantation of HSCs from bone marrow, peripheral blood or cord blood is currently one of the most popular stem cell therapies in blood system diseases (103). HSC transplantation (HSCT) is a therapeutic method in which patients receive a massive high-dose of radiotherapy or chemotherapy (usually a lethal dose of radiotherapy or chemotherapy), occasionally combined with other immunosuppressive drugs to remove tumor cells and aberrant clonal cells in the body, and then reinfuse the HSCs collected from the patients themselves or other individuals to reconstruct normal hematopoietic and immune functions (104). HSCT is widely used in the treatment of hematological malignancies, such as acute leukemia, CML, lymphoma, multiple myeloma (MM), myelodysplastic syndrome (MDS), and certain hematological non-malignant tumors, such as severe aplastic anemia (AA) and thalassemia (105). The process may be autologous (using the patient's own cells), allogeneic (stem cells from a donor), or syngeneic (from identical twins) (2). For numerous types of leukemia, allogeneic HSCT (allo-HSCT) is a more suitable standard cell treatment option than autologous HSCT (auto-HSCT) (106-110) (Table II).

In view of the fact that HSCs are derived from the patients themselves during the process of auto-HSCT, there will be no graft rejection and graft-vs.-host disease (GVHD) and there are few transplantation complications. The low transplant-related mortality and favorable quality of life following transplantation are due to the no limitation of donor constraints. However, given the lack of graft antitumor effect and the possibility of residual tumor cells in the graft, the recurrence rate is high. Auto-HSCT has become a routine treatment option for patients with lymphoma (111), certain low-risk acute leukemias (112), highly invasive, relapsed/refractory non-Hodgkin's lymphoma (NHL) (113) and MM (114). For example, the clinical efficacy of auto-HSCT for AML has gradually improved. A group of European researchers retrospectively analyzed the survival outcomes of 809 patients with AML in their first complete response and identified that the 2-year leukemia-free survival rate and overall survival rate were 51 and $65 \%$, respectively, and the non-recurrence mortality rate was only $3.7 \%$ (115). Taking it a step further, Passweg (116) revealed that the 3-year overall survival rate of AML was 34 (21-56)\% following chemotherapy, but 75 (60-95)\% following consolidation with auto-HSCT. In fact, a large number of studies have revealed that auto-HSCT is associated with lower recurrence rates and an acceptable non-recurrent mortality rate in AML patients compared with chemotherapy alone (115). In addition, in certain AML patients, auto-HSCT was comparable to allo-HSCT in overall survival (116).

The HSCs in allo-HSCT are derived from normal donors without tumor cell contamination. Considering the immune-antitumor effect of the graft, it has a low recurrence rate, a high long-term disease-free survival rate (also known as cure rate), a wide range of indications, and is even the only cure for certain diseases (114). However, due to the limited sources of donors, GVHD is prone to occur with numerous transplant complications, leading to high graft-related mortality. Therefore, patients need to be treated with immunosuppressants for a long period of time, and the quality of life of long-term survivors may be poor. Patients at moderate or high risk for acute leukemia (117), AML (118), MDS (119), severe AA (120), and thalassemia (121) are suitable for allo-HSCT (122). To date, allo-HSCT remains the only radical treatment for CML. Allo-HSCT is exhibiting better results in 
the treatment of CML due to improved HLA gene matching techniques, the use of tyrosine kinase inhibitors, advances in postoperative immune status and fusion gene monitoring and improvements in postoperative complications, particularly GVHD (123). Similar to CML, allo-HSCT is effective in alleviating highly complex and severe AML. However, relapse is a major cause of treatment failure for AML patients undergoing allo-HSCT. Therefore, an effective and safe approach is required, in the future, to improve survival following remission of AML (117). In addition, a female patient with adult T-cell leukemia/lymphoma involving bone, skin, and skeletal muscle exhibited a favorable post-transplant course after receiving cyclophosphamide following allo-HSCT from her son in a clinical case report (124). There has been no progression of disease for more than two years, suggesting that this approach offers a well-tolerated and potentially curable treatment for this hard-to-treat disease (124). Given the high toxicity of this treatment, graft-anti-leukemia response and the high recurrence and mortality rate, novel post-transplantation maintenance regimens need to be studied.

In a series of studies, it was revealed that the Notch1/Fbxw7 mutations in T-ALL patients may be useful biomarkers for predicting the prognosis of T-ALL. In a survey of 50 patients with T-ALL in southern India, there were 20 out of the $50(40 \%)$ patients with Notch1/Fbxw7 mutations among which the 13 out of the 20 (65\%) T-ALL patients with Notch1/Fbxw7 mutations exhibited favorable prednisone responses $(\mathrm{P}=0.01)$ and improved clinical outcomes compared with patients without Notch1/Fbxw7 mutations $(\mathrm{P}=0.03)(125)$. In the survival analysis of the sample $(\mathrm{n}=50)$ studied by Valliyammai et al $(126)$, it was determined that patients with Notch1/Fbxw7 hotspot mutation had earlier response to treatment and improved survival. Additionally, it was suggested that Notch1/Fbxw7 hotspot-mutated T-ALL cases responded better to the ALL BFM-95 protocol. Furthermore, pediatric T-ALL patients with either double Notchl mutations (Notch1 ${ }^{\text {Double }}$ Fbxw $7^{\text {WT }}$ ) or mutations in both genes (Notch $\left.1^{M U T} F b x w 7^{M U T}\right)$, hereafter termed as Notch $1 \pm F b x w 7^{\text {Double }}$, had an improved outcome (127). Jenkinson et al (127) screened 162 pediatric T-ALL patients treated in the MRC UKALL2003 trial for Notchl/Fbxw7 gene mutations and associated genotypes in response to treatment and long-term outcomes. Of the 162 patients, 57 (35\%) patients were both Notchl and Fbxw7 wild-type, $62(38 \%)$ patients had single Notchl mutations, $5(3 \%)$ patients had single Fbxw7 mutations, and 39 (24\%) patients had Notch1 $\pm F b x w 7^{\text {Double }}$. It was revealed that while 14 Notch $1 \pm$ Fbxw $7^{\text {Double }}$ patients were classified as high risk, only 2 patients progressed in disease and all survived. Collectively, these data suggested that detecting the Fbxw7 mutations adds important prognostic value to the separate assessment of Notchl status, justifies individual treatment stratification of T-ALL (128), and allows the identification of the majority (72\%) of Notch1/Fbxw7-mutated T-ALL patients with a relatively favorable prognosis, who cannot be treated with more classical, clinical, immunophenotypic or carcinogenic markers (128). Conversely, loss of Fbxw7 in primary T-ALL has also been reported to provide a favorable prognosis for patients. Loss of $F b x w 7$ reduces ubiquitination modification and degradation of glucocorticoid receptor $\alpha$, thus enhancing glucocorticoid sensitivity. This increased sensitivity can enhance glucocorticoid response to treatment and provide a favorable prognosis for T-ALL (129).

In addition, several studies identified $\mathrm{Cbl}$ and $\mathrm{Fbxw} 7$ as new targets for anti-Notch1 therapy. Saito et al (130) revealed that flavonoids induced N1ICD degradation through the UPS by increasing $\mathrm{Cbl}$ in T-ALL. Flavonoid-induced resistance to T-ALL was also revealed, and Cbl was identified as a new N1ICD binding partner critical for regulating its stability and carcinogenic function. In the case of Fbxw7, oridonin has exhibited an anti-leukemia activity in vitro and in vivo by promoting Fbxw7-mediated ubiquitination modification and degradation of myc (131). These studies suggest that flavonoid and oridonin are potential drugs for T-ALL.

\section{Conclusions and perspectives}

Notch signaling, particularly Notch1 receptor, is the primary regulator of HSC stemness in embryos and adulthood, and its role in inducing leukemia (e.g., T-ALL) has been detailed in a variety of studies $(52-55,132)$. In general, Notch1 can promote the proliferation of HSCs and inhibit its differentiation (133). However, due to the context dependence of the Notch signaling pathway and activation by different ligands, Notch1 receptor can also partially inhibit the proliferation of HSCs and promote their differentiation. Additionally, the lifetime and activity of the Notch1 receptor is largely determined by the UPS that regulates Notch1 receptor degradation, activation of Notch1 signaling, and Notch1 receptor endocytosis and its subsequent fate. Additionally, the signaling enhancement or mutations of the Notch1 pathway and the dysregulations or mutations of Notch1-related UPS have been demonstrated to be closely associated with the aberrancy of HSCs and the occurrence of leukemia (134). Therefore, further revealing the details of this pathway and the factors that regulate the UPS could help improve the treatment and prognosis of leukemia.

Since the present review is limited to the effects of Notch1 receptor and its ubiquitination modification on HSCs, other receptors and ligands of the Notch signaling pathway, or other regulatory modes of this pathway such as phosphorylation, require clarification. In addition, several studies have revealed that Notch signaling interacts closely with other signaling pathways, such as the Wnt, hippo, TGF- $\beta$ family and Hedgehog that regulate stem cell properties, but these associations have not been well elucidated (135-139). Therefore, future research may also focus on the interactions or crosstalk between these pathways.

Currently, Notch1 and Fbxw7 are mainly used as prognostic indicators of T-ALL (140). However, studies on these two proteins and their regulators as treatments for leukemia are urgent. In particular, their application as therapeutic targets for leukemia or in combination with other chemotherapeutic agents require further study. In addition, it is necessary to examine whether they can be used as prognostic indicators for auto-HSCT or allo-HSCT.

\section{Acknowledgements}

Not applicable. 


\section{Funding}

The present review was supported by The Fundamental Research Funds for the Provincial Universities of Zhejiang, The Natural Science Foundation of Zhejiang Province (grant no. LY20C070001), The National Natural Science Foundation of China (grant no. 31801165), and The K.C. Wong Magna Fund of Ningbo University.

\section{Availability of data and materials}

Not applicable.

\section{Authors' contributions}

XJ, MY, YG, HZ, JW and JL made substantial contributions to conception and design. XJ, YG, HZ, JW and JL were involved in drafting the manuscript and revising it critically for important intellectual content. XJ, MY, YG, HZ, JW and $\mathrm{JL}$ agreed to be accountable for all aspects of the work. All authors read and approved the final manuscript for publication. Data authentication is not applicable.

\section{Ethics approval and consent to participate}

Not applicable.

\section{Patient consent for publication}

Not applicable.

\section{Competing interests}

The authors declare that they have no competing interests.

\section{References}

1. Nawab K, Bhere D, Bommarito A, Mufti M and Naeem A: Stem cell therapies: A way to promising cures. Cureus 11: e5712, 2019.

2. Zakrzewski W, Dobrzynski M, Szymonowicz M and Rybak Z: Stem cells: Past, present, and future. Stem Cell Res Ther 10: 68, 2019.

3. Wang D, Bu F and Zhang W: The role of Ubiquitination in regulating embryonic stem cell maintenance and cancer development. Int J Mol Sci 20: 2667, 2019.

4. Wang X: Stem cells in tissues, organoids, and cancers. Cell Mol Life Sci 76: 4043-4070, 2019.

5. Aponte PM and Caicedo A: Stemness in cancer: Stem cells, cancer stem cells, and their microenvironment. Stem Cells Int 2017: 5619472, 2017.

6. Ruan Y, Kim HN, Ogana H and Kim YM: Wnt signaling in leukemia and its bone marrow microenvironment. Int J Mol Sci 21: 6247, 2020.

7. Roo JJD and Staal FJT: Cell signaling pathway reporters in adult hematopoietic stem cells. Cells 9: 2264, 2020.

8. Althoff MJ, Nayak RC, Hegde S, Wellendorf AM, Bohan B, Filippi MD, Xin M, Lu QR, Geiger $\mathrm{H}$, Zheng $\mathrm{Y}$, et al: Yap1-Scribble polarization is required for hematopoietic stem cell division and fate. Blood 136: 1824-1836, 2020.

9. Pajcini KV, Speck NA and Pear WS: Notch signaling in mammalian hematopoietic stem cells. Leukemia 25: 1525-1532, 2011.

10. Palomero T and Ferrando A: Oncogenic NOTCH1 control of MYC and PI3K: Challenges and opportunities for anti-NOTCH1 therapy in T-cell acute lymphoblastic leukemias and lymphomas. Clin Cancer Res 14: 5314-5317, 2008.

11. Pettersson S, Sczaniecka M, McLaren L, Russell F, Gladstone K, Hupp T and Wallace M: Non-degradative ubiquitination of the Notch1 receptor by the E3 ligase MDM2 activates the Notch signalling pathway. Biochem J 450: 523-536, 2013.
12. Kar R, Jha SK, Ojha S, Sharma A, Dholpuria S, Raju VSR, Prasher P, Chellappan DK, Gupta G, Kumar Singh S, et al: The FBXW7-NOTCH interactome: A ubiquitin proteasomal system-induced crosstalk modulating oncogenic transformation in human tissues. Cancer Rep (Hoboken) 4: e1369, 2021.

13. Hori K, Sen A, Kirchhausen T and Artavanis-Tsakonas S: Synergy between the ESCRT-III complex and Deltex defines a ligand-independent Notch signal. J Cell Biol 195: 1005-1015, 2011.

14. King B, Trimarchi T, Reavie L, Xu L, Mullenders J, Ntziachristos P, Aranda-Orgilles B, Perez-Garcia A, Shi J, Vakoc C, et al: The ubiquitin ligase FBXW7 modulates leukemia-initiating cell activity by regulating MYC stability. Cell 153: 1552-1566, 2013.

15. Thompson BJ, Buonamici S, Sulis ML, Palomero T, Vilimas T, Basso G, Ferrando A and Aifantis I: The SCFFBW7 ubiquitin ligase complex as a tumor suppressor in T cell leukemia. J Exp Med 204: 1825-1835, 2007.

16. Zhu W, Zhu Y, Xu H, Wang T, Wang J, Meng M, Liu Y, Yan H, Yang Q and Liu P: Flavone inhibited proliferation of T-ALL by promoting c-Cbl-induced ubiquitinylation and degradation of Notch1. Biochem Biophys Res Commun 522: 684-689, 2020.

17. Zieba JT, Chen YT, Lee BH and Bae Y: Notch signaling in skeletal development, homeostasis and pathogenesis. Biomolecules 10: 332, 2020.

18. Chikara S and Reindl KM: Notch signaling: A hero or villain in the war against cancer? Transl Lung Cancer Res 2: 449-451, 2013.

19. Jundt F, Anagnostopoulos I, Forster R, Mathas S, Stein H and Dorken B: Activated Notch1 signaling promotes tumor cell proliferation and survival in Hodgkin and anaplastic large cell lymphoma. Blood 99: 3398-3403, 2002.

20. Li L, Tang P, Li S, Qin X, Yang H, Wu C and Liu Y: Notch signaling pathway networks in cancer metastasis: A new target for cancer therapy. Med Oncol 34: 180, 2017.

21. Espinoza I, Pochampally R, Xing F, Watabe K and Miele L: Notch signaling: Targeting cancer stem cells and epithelial-to-mesenchymal transition. Onco Targets Ther 6: 1249-1259, 2013.

22. Wu J and Bresnick EH: Bare rudiments of notch signaling: How receptor levels are regulated. Trends Biochem Sci 32: 477-485, 2007.

23. Meloty-Kapella L, Shergill B, Kuon J, Botvinick E and Weinmaster G: Notch ligand endocytosis generates mechanical pulling force dependent on dynamin, epsins, and actin. Dev Cell 22: 1299-1312, 2012.

24. Fischer A and Gessler M: Delta-Notch-and then? Protein interactions and proposed modes of repression by Hes and Hey bHLH factors. Nucleic Acids Res 35: 4583-4596, 2007.

25. Bessho Y, Sakata R, Komatsu S, Shiota K, Yamada S and Kageyama R: Dynamic expression and essential functions of Hes7 in somite segmentation. Genes Dev 15: 2642-2647, 2001.

26. Fischer A, Schumacher N, Maier M, Sendtner M and Gessler M: The Notch target genes Heyl and Hey2 are required for embryonic vascular development. Genes Dev 18: 901-911, 2004.

27. Dohda T, Maljukova A, Liu L, Heyman M, Grandér D, Brodin D, Sangfelt $\mathrm{O}$ and Lendahl U: Notch signaling induces SKP2 expression and promotes reduction of p27Kip1 in T-cell acute lymphoblastic leukemia cell lines. Exp Cell Res 313: 3141-3152, 2007.

28. Ronchini $\mathrm{C}$ and Capobianco AJ: Induction of cyclin D1 transcription and CDK2 activity by Notch(ic): Implication for cell cycle disruption in transformation by Notch(ic). Mol Cell Biol 21: 5925-5934, 2001.

29. Demarest RM, Dahmane N and Capobianco AJ: Notch is oncogenic dominant in T-cell acute lymphoblastic leukemia. Blood 117: 2901-2909, 2011.

30. Zhang P, Yang Y, Nolo R, Zweidler-McKay PA and Hughes DPM: Regulation of NOTCH signaling by reciprocal inhibition of HES1 and Deltex 1 and its role in osteosarcoma invasiveness. Oncogene 29: 2916-2926, 2010.

31. Dutta D, Sharma V, Mutsuddi M and Mukherjee A: Regulation of Notch signaling by E3 ubiquitin ligases. FEBS J: Feb 28, 2021 (Epubs ahead of print). doi: 10.1111/febs.15792.

32. Seita J and Weissman IL: Hematopoietic stem cell: Self-renewal versus differentiation. Wiley Interdiscip Rev Syst Biol Med 2: 640-653, 2010.

33. Sinka L, Biasch K, Khazaal I, Peault B and Tavian M: Angiotensin-converting enzyme (CD143) specifies emerging lympho-hematopoietic progenitors in the human embryo. Blood 119: 3712-3723, 2012.

34. Suzuki T and Chiba S: Notch signaling in hematopoietic stem cells. Int J Hematol 82: 285-294, 2005. 
35. Saito K, Nobuhisa I, Harada K, Takahashi S, Anani M, Lickert H, Kanai-Azuma M, Kanai Y and Taga T: Maintenance of hematopoietic stem and progenitor cells in fetal intra-aortic hematopoietic clusters by the Sox17-Notch1-Hes1 axis. Exp Cell Res 365: 145-155, 2018.

36. Zhang P, He Q, Chen D, Liu W, Wang L, Zhang C, Ma D, Li W, Liu B and Liu F: G protein-coupled receptor 183 facilitates endothelial-to-hematopoietic transition via Notch1 inhibition. Cell Res 25: 1093-1107, 2015.

37. Kumano K, Chiba S, Kunisato A, Sata M, Saito T, Nakagami-Yamaguchi E, Yamaguchi T, Masuda S, Shimizu K, Takahashi T, et al: Notch1 but Not Notch2 is essential for generating hematopoietic stem cells from endothelial cells Immunity 18: 699-711, 2003.

38. Gama-Norton L, Ferrando E, Ruiz-Herguido C, Liu Z, Guiu J, Islam AB, Lee SU, Yan M, Guidos CJ, López-Bigas N, et al: Notch signal strength controls cell fate in the haemogenic endothelium. Nat Commun 6: 8510, 2015.

39. Jang IH, Lu YF, Zhao L, Wenzel PL, Kume T, Datta SM Arora N, Guiu J, Lagha M, Kim PG, et al: Notch1 acts via Foxc2 to promote definitive hematopoiesis via effects on hemogenic endothelium. Blood 125: 1418-1426, 2015.

40. Stier S, Cheng T, Dombkowski D, Carlesso N and Scadden DT: Notch1 activation increases hematopoietic stem cell self-renewa in vivo and favors lymphoid over myeloid lineage outcome. Blood 99: 2369-2378, 2002.

41. Shao L, Paik NY and Pajcini KV: Hematopoietic jagged1 is required for the transition of hematopoietic stem cells from the fetal liver to the adult bone marrow niche. Blood 136: 10-11, 2020.

42. Ishiko E, Matsumura I, Ezoe S, Gale K, Ishiko J, Satoh Y, Tanaka H, Shibayama H, Mizuki M, Era T, et al: Notch signals inhibit the development of erythroid/megakaryocytic cells by suppressing GATA-1 activity through the induction of HES1. J Biol Chem 280: 4929-4939, 2005.

43. Henning K, Heering J, Schwanbeck R, Schroeder T, Helmbold H, Schäfer H, Deppert W, Kim E and Just U: Notch1 activation reduces proliferation in the multipotent hematopoietic progenitor cell line FDCP-mix through a p53-dependent pathway but Notch1 effects on myeloid and erythroid differentiation are independent of p53. Cell Death Differ 15: 398-407, 2008

44. Yashiro-Ohtani Y, Ohtani T and Pear WS: Notch regulation of early thymocyte development. Semin Immunol 22: 261-269, 2010.

45. Allman D, Karnell FG, Punt JA, Bakkour S, Xu L, Myung P, Koretzky GA, Pui JC, Aster JC and Pear WS: Separation of Notch1 promoted lineage commitment and expansion/transformation in developing T cells. J Exp Med 194: 99-106, 2001.

46. Gerhardt DM, Pajcini KV, D'Altri T, Tu L, Jain R, Xu L, Chen MJ, Rentschler S, Shestova O, Wertheim GB, et al: The Notch1 transcriptional activation domain is required for development and reveals a novel role for Notch1 signaling in fetal hematopoietic stem cells. Genes Dev 28: 576-593, 2014.

47. Deftos ML and Bevan MJ: Notch signaling in T cell development. Curr Opin Immunol 12: 166-172, 2000.

48. Tomita K, Hattori M, Nakamura E, Nakanishi S, Minato N and Kageyama R: The bHLH gene Hes1 is essential for expansion of early T cell precursors. Genes Dev 13: 1203-1210, 1999.

49. De Decker M, Lavaert M, Roels J, Tilleman L, Vandekerckhove B, Leclercq G, Van Nieuwerburgh F, Van Vlierberghe P and Taghon T: HES1 and HES4 have non-redundant roles downstream of Notch during early human T-cell development. Haematologica 106: 130-141, 2021.

50. Haque R, Song J, Haque M, Lei F, Sandhu P, Ni B, Zheng S, Fang D, Yang JM and Song J: c-Myc-Induced survivin is essential for promoting the Notch-dependent $\mathrm{T}$ cell differentiation from hematopoietic stem cells. Genes (Basel) 8: 97, 2017.

51. Van de Walle I, De Smet G, Gärtner M, De Smedt M, Waegemans E, Vandekerckhove B, Leclercq G, Plum J, Aster JC, Bernstein ID, et al: Jagged2 acts as a Delta-like Notch ligand during early hematopoietic cell fate decisions. Blood 117: 4449-4459, 2011

52. Wendorff AA and Ferrando AA: Modeling NOTCH1 driven T-cell acute lymphoblastic leukemia in mice. Bio Protoc 10 : e3620, 2020

53. Ma W, Gutierrez A, Goff DJ, Geron I, Sadarangani A, Jamieson CA, Court AC, Shih AY, Jiang Q, Wu CC, et al: NOTCH1 signaling promotes human T-cell acute lymphoblastic leukemia initiating cell regeneration in supportive niches. PLoS One 7: e39725, 2012.
54. Bhanushali AA, Babu S, Thangapandi VR, Pillai R, Chheda P and Das BR: Mutations in the HD and PEST domain of Notch-1 receptor in T-cell acute lymphoblastic leukemia: Report of novel mutations from Indian population. Oncol Res 19: 99-104, 2010.

55. Ding J, Cardoso AA, Yoshimoto $M$ and Kobayashi M: The Earliest T-Precursors in the mouse embryo are susceptible to leukemic transformation. Front Cell Dev Biol 9: 634151, 2021.

56. Di Ianni M, Baldoni S, Del Papa B, Aureli P, Dorillo E, De Falco F, Albi E, Varasano E, Di Tommaso A, Giancola R, et al: NOTCH1 is aberrantly activated in chronic lymphocytic leukemia hematopoietic stem cells. Front Oncol 8: 105, 2018.

57. Spit M, Rieser E and Walczak H: Linear ubiquitination at a glance. J Cell Sci 132: jes208512, 2019.

58. Mansour MA: Ubiquitination: Friend and foe in cancer. Int J Biochem Cell Biol 101: 80-93, 2018.

59. Martins S, Dohmann EMN, Cayrel A, Johnson A, Fischer W, Pojer F, Satiat-Jeunemaître B, Jaillais Y, Chory J, Geldner N and Vert G: Author Correction: Internalization and vacuolar targeting of the brassinosteroid hormone receptor BRI1 are regulated by ubiquitination. Nat Commun 12: 2982, 2021.

60. Barbosa P, Zhaunova L, Debilio S, Steccanella V, Kelly V, Ly T and Ohkura H: SCF-Fbxo42 promotes synaptonemal complex assembly by downregulating PP2A-B56. J Cell Biol 220: e202009167, 2021.

61. Li ZQ, Chen X and Wang Y: Small molecules targeting ubiquitination to control inflammatory diseases. Drug Discov Today 26: 2414-2422, 2021

62. Dybas JM, Herrmann C and Weitzman MD: Ubiquitination at the interface of tumor viruses and DNA damage responses. Curr Opin Virol 32: 40-47, 2018

63. Seo J, Kim MW, Bae KH, Lee SC, Song J and Lee EW: The roles of ubiquitination in extrinsic cell death pathways and its implications for therapeutics. Biochem Pharmacol 162: 21-40, 2019.

64. Sun T, Liu Z and Yang Q: The role of ubiquitination and deubiquitination in cancer metabolism. Mol Cancer 19: 146, 2020.

65. Zuo Y, Feng Q, Jin L, Huang F, Miao Y, Liu J, Xu Y, Chen X, Zhang H, Guo T, et al: Regulation of the linear ubiquitination of STAT1 controls antiviral interferon signaling. Nat Commun 11: 1146,2020

66. Liu Y and Deng J: Ubiquitinationdeubiquitination in the Hippo signaling pathway (Review). Oncol Rep 41: 1455-1475, 2019.

67. Soysouvanh F, Giuliano S, Habel N, El-Hachem N, Pisibon C, Bertolotto C and Ballotti R: An Update on the role of ubiquitination in melanoma development and therapies. J Clin Med 10: 113, 2021.

68. Jeusset LM and McManus KJ: Developing targeted therapies that exploit aberrant histone ubiquitination in cancer. Cells 8 : 165,2019

69. Celebi G, Kesim H, Ozer E and Kutlu O: The effect of dysfunctional ubiquitin enzymes in the pathogenesis of most common diseases. Int J Mol Sci 21: 6335, 2020

70. Liu BQ, Jin J and Li YY: Ubiquitination modification: Critical regulation of IRF family stability and activity. Sci China Life Sci 64: 957-965, 2021

71. Chen RH, Chen YH and Huang TY: Ubiquitin-mediated regulation of autophagy. J Biomed Sci 26: 80, 2019.

72. Song YQ, Wu C, Wu KJ, Han QB, Miao XM, Ma DL and Leung $\mathrm{CH}$ : Ubiquitination regulators discovered by virtual screening for the treatment of cancer. Front Cell Dev Biol 9: 665646, 2021.

73. Gupta-Rossi N, Le Bail O, Gonen H, Brou C, Logeat F, Six E, Ciechanover A and Israël A: Functional interaction between SEL-10, an F-box protein, and the nuclear form of activated Notch1 receptor. J Biol Chem 276: 34371-34378, 2001.

74. Fostier M, Evans DA, Artavanis-Tsakonas S and Baron M: Genetic characterization of the Drosophila melanogaster Suppressor of deltex gene: A regulator of notch signaling. Genetics 150: 1477-1485, 1998.

75. Cornell M, Evans DA, Mann R, Fostier M, Flasza M, Monthatong M, Artavanis-Tsakonas S and Baron M: The Drosophila melanogaster Suppressor of deltex gene, a regulator of the Notch receptor signaling pathway, is an E3 class ubiquitin ligase. Genetics 152: 567-576, 1999.

76. Qiu L, Joazeiro C, Fang N, Wang HY, Elly C, Altman Y, Fang D, Hunter T and Liu YC: Recognition and ubiquitination of Notch by Itch, a hect-type E3 ubiquitin ligase. J Biol Chem 275: 35734-35737, 2000.

77. McGill MA and McGlade CJ: Mammalian numb proteins promote Notch1 receptor ubiquitination and degradation of the Notch1 intracellular domain. J Biol Chem 278: 23196-23203, 2003. 
78. Che F, Chen J, Wan C and Huang X: MicroRNA-27 inhibits autophagy and promotes proliferation of multiple myeloma cells by targeting the NEDD4/Notch1 Axis. Front Oncol 10: 571914, 2020.

79. Baron M: Endocytic routes to Notch activation. Semin Cell Dev Biol 23: 437-442, 2012.

80. Wilkin M, Tongngok P, Gensch N, Clemence S, Motoki M, Yamada K, Hori K, Taniguchi-Kanai M, Franklin E, Matsuno K and Baron M: Drosophila HOPS and AP-3 complex genes are required for a Deltex-regulated activation of notch in the endosomal trafficking pathway. Dev Cell 15: 762-772, 2008.

81. Jehn BM, Dittert I, Beyer S, von der Mark K and Bielke W: c-Cbl binding and ubiquitin-dependent lysosomal degradation of membrane-associated Notch1. J Biol Chem 277: 8033-8040, 2002.

82. Wu G, Lyapina S, Das I, Li J, Gurney M, Pauley A, Chui I, Deshaies RJ and Kitajewski J: SEL-10 is an inhibitor of notch signaling that targets notch for ubiquitin-mediated protein degradation. Mol Cell Biol 21: 7403-7415, 2001.

83. Li L, Guturi KKN, Gautreau B, Patel PS, Saad A, Morii M, Mateo F, Palomero L, Barbour H, Gomez A, et al: Ubiquitin ligase RNF8 suppresses Notch signaling to regulate mammary development and tumorigenesis. J Clin Invest 128: 4525-4542, 2018.

84. McGill MA, Dho SE, Weinmaster G and McGlade CJ: Numb regulates post-endocytic trafficking and degradation of Notch1. J Biol Chem 284: 26427-26438, 2009.

85. Chastagner P, Israel A and Brou C: AIP4/Itch regulates Notch receptor degradation in the absence of ligand. PLoS One 3: e2735, 2008.

86. Sakata T, Sakaguchi H, Tsuda L, Higashitani A, Aigaki T, Matsuno K and Hayashi S: Drosophila Nedd4 regulates endocytosis of notch and suppresses its ligand-independent activation. Curr Biol 14: 2228-2236, 2004.

87. Henne WM, Buchkovich NJ and Emr SD: The ESCRT pathway. Dev Cell 21: 77-91, 2011

88. Moretti $\mathrm{J}$ and Brou $\mathrm{C}$ : Ubiquitinations in the notch signaling pathway. Int J Mol Sci 14: 6359-6381, 2013

89. MacDonald C, Buchkovich NJ, Stringer DK, Emr SD and Piper RC: Cargo ubiquitination is essential for multivesicular body intralumenal vesicle formation. EMBO Rep 13: 331-338, 2012.

90. Perry JM and Li L: Self-renewal versus transformation: Fbxw7 deletion leads to stem cell activation and leukemogenesis. Genes Dev 22: 1107-1109, 2008.

91. Iriuchishima H, Takubo K, Matsuoka S, Onoyama I, Nakayama KI, Nojima Y and Suda T: Ex vivo maintenance of hematopoietic stem cells by quiescence induction through Fbxw7 $\alpha$ overexpression. Blood 117: 2373-2377, 2011.

92. Thompson BJ, Jankovic V, Gao J, Buonamici S, Vest A, Lee JM, Zavadil J, Nimer SD and Aifantis I: Control of hematopoietic stem cell quiescence by the E3 ubiquitin ligase Fbw7. J Exp Med 205: 1395-1408, 2008.

93. Matsuoka S, Oike Y, Onoyama I, Iwama A, Arai F, Takubo K, Mashimo Y, Oguro H, Nitta E, Ito K, et al: Fbxw7 acts as a critical fail-safe against premature loss of hematopoietic stem cells and development of T-ALL. Genes Dev 22: 986-991, 2008.

94. Rathinam C, Thien CB, Langdon WY, Gu H and Flavell RA: The E3 ubiquitin ligase c-Cbl restricts development and functions of hematopoietic stem cells. Genes Dev 22: 992-997, 2008.

95. Rathinam C, Matesic LE and Flavell RA: The E3 ligase Itch is a negative regulator of the homeostasis and function of hematopoietic stem cells. Nat Immunol 12: 399-407, 2011.

96. Asgarpour K, Shojaei Z, Amiri F, Ai J, Mahjoubin-Tehran M, Ghasemi F, ArefNezhad R, Hamblin MR and Mirzaei H: Exosomal microRNAs derived from mesenchymal stem cells: Cell-to-cell messages. Cell Commun Signal 18: 149, 2020.

97. Moradian Tehrani R, Verdi J, Noureddini M, Salehi R, Salarinia R, Mosalaei M, Simonian M, Alani B, Ghiasi MR, Jaafari MR, et al: Mesenchymal stem cells: A new platform for targeting suicide genes in cancer. J Cell Physiol 233: 3831-3845, 2018.

98. Mirzaei H, Sahebkar A, Avan A, Jaafari MR, Salehi R, Salehi H, Baharvand H, Rezaei A, Hadjati J, Pawelek JM and Mirzaei HR Application of mesenchymal stem cells in melanoma: A potential therapeutic strategy for delivery of targeted agents. Curr Med Chem 23: 455-463, 2016

99. Mirzaei H, Salehi H, Oskuee RK, Mohammadpour A, Mirzaei HR, Sharifi MR, Salarinia R, Darani HY, Mokhtari M, Masoudifar A, et al: The therapeutic potential of human adipose-derived mesenchymal stem cells producing CXCL10 in a mouse melanoma lung metastasis model. Cancer Lett 419: 30-39, 2018.
100. Mianehsaz E, Mirzaei HR, Mahjoubin-Tehran M, Rezaee A, Sahebnasagh R, Pourhanifeh MH, Mirzaei H and Hamblin MR: Mesenchymal stem cell-derived exosomes: A new therapeutic approach to osteoarthritis? Stem Cell Res Ther 10: 340, 2019.

101. Goradel NH, Hour FG, Negahdari B, Malekshahi ZV, Hashemzehi M, Masoudifar A and Mirzaei H: Stem cell therapy: A new therapeutic option for cardiovascular diseases. J Cell Biochem 119: 95-104, 2018.

102. Mohammadi M, Jaafari MR, Mirzaei HR and Mirzaei H: Mesenchymal stem cell: a new horizon in cancer gene therapy. Cancer Gene Ther 23: 285-286, 2016.

103. Hatzimichael E and Tuthill M: Hematopoietic stem cell transplantation. Stem Cells Cloning 3: 105-117, 2010.

104. Walsh K, Margossian S and Duncan CN: Pediatric hematopoietic cell transplantation. J Pediatr Intensive Care 3: 91-101, 2014

105. Dessie G, Derbew Molla M, Shibabaw T and Ayelign B: Role of stem-cell transplantation in leukemia treatment. Stem Cells Cloning 13: 67-77, 2020.

106. Vanderwalde AM, Sun CL, Laddaran L, Francisco L, Armenian S, Berano-Teh J, Wong FL, Popplewell L, Somlo G, Stein AS, et al: Conditional survival and cause-specific mortality after autologous hematopoietic cell transplantation for hematological malignancies. Leukemia 27: 1139-1145, 2013.

107. Wang Y, Chen H, Chen J, Han M, Hu J, Jiong Hu, Huang H, Lai Y, Liu D, Liu Q, et al: The consensus on the monitoring, treatment, and prevention of leukemia relapse after allogeneic hematopoietic stem cell transplantation in China. Cancer Lett 438: 63-75, 2018.

108. Copelan EA: Medical progress: Hematopoietic stem-cell transplantation. N Engl J Med 354: 1813-1826, 2006.

109. Doubek M, Folber F, Koristek Z, Brychtova Y, Krejci M, Tomiska M, Navratil M, Mikulasova P and Mayer J: Autologous hematopoietic stem cell transplantation in adult acute lymphoblastic leukemia: Still not out of fashion. Ann Hematol 88: 881-887, 2009.

110. Atsuta Y, Hirakawa A, Nakasone H, Kurosawa S, Oshima K, Sakai R, Ohashi K, Takahashi S, Mori T, Ozawa Y, et al: Late mortality and causes of death among long-term survivors after allogeneic stem cell transplantation. Biol Blood Marrow Transplant 22: 1702-1709, 2016.

111. Wang X, Xia B and Zhang YZ: Progress of Auto-HSCT for treatment of DLBCL-review. Zhongguo Shi Yan Xue Ye Xue Za Zhi 26: 1841-1846, 2018 (In Chinese).

112. Alimoghaddam K, Ghavamzadeh A, Jahani M, Jalali A, Jorjani H, Iravani M, Hamidieh AA, Mousavi A, Bahar B, Behfar M, et al: Hematopoietic stem cell transplantation in acute promyelocytic leukemia, experience in Iran. Arch Iran Med 14: 332-334, 2011.

113. Zhu J: Thoughts on autologous hematopoietic stem cell transplantation and mobilization in Chinese patients with non Hodgkin's lymphoma. Zhonghua Xue Ye Xue Za Zhi 41: 1-4, 2020 (In Chinese).

114. Liu JR, Li J and Huang XJ: Problems and progress of autologous hematopoietic stem cell transplantation in multiple myeloma. Zhonghua Xue Ye Xue Za Zhi 42: 82-86, 2021 (In Chinese).

115. Zhao Y, Chen X and Feng S: Autologous hematopoietic stem cell transplantation in acute Myelogenous leukemia. Biol Blood Marrow Transplant 25: e285-e292, 2019.

116. Passweg JR: Autologous hematopoetic cell transplantation: Preferred consolidation treatment in low-risk AML? Leuk Lymphoma 60: 2341-2342, 2019.

117. Xuan L and Liu Q: Maintenance therapy in acute myeloid leukemia after allogeneic hematopoietic stem cell transplantation. J Hematol Oncol 14: 4, 2021.

118. Yong AS, Brissot E, Rubinstein S, Savani BN and Mohty M: Transplant to treatment-free remission: The evolving view of 'cure' in chronic myeloid leukemia. Expert Rev Hematol 8: 785-797, 2015.

119. Kook MH, Yhim HY, Lee NR, Song EK, Kim HS, Yim CY and Kwak JY: Successful treatment of myelodysplastic syndrome and Behcet colitis after allogeneic hematopoietic stem cell transplantation. Korean J Intern Med 29: 123-125, 2014.

120. Chen X and Feng SZ: Advances in allogeneic hematopoietic stem cell transplantation for severe aplastic anemia. Zhonghua Xue Ye Xue Za Zhi 33: 963-967, 2012 (In Chinese).

121. Peters C: Allogeneic hematopoietic stem cell transplantation to cure transfusion-dependent thalassemia: Timing Matters! Biol Blood Marrow Transplant 24: 1107-1108, 2018. 
122. Del Galy AS, Marouf A, Raffoux E, Robin M, Michonneau D, Sébert M, Sicre de Fontebrune F, Xhaard A, Lengline E, Itzykson R, et al: Correction to: Allogeneic hematopoietic stem cell transplantation in elderly patients with acute myeloid leukemia or myelodysplastic syndromes: Myth and reality. Leukemia 35: 934, 2021.

123. Chen XP, Cao ZR and Hu J: Advances in allogeneic hematopoietic stem cell transplantation for chronic Myelogenous leukemia-review. Zhongguo Shi Yan Xue Ye Xue Za Zhi 27: 1334-1338, 2019 (In Chinese).

124. Iioka F, Tanabe H, Honjo G, Misaki T and Ohno H: Resolution of bone, cutaneous, and muscular involvement after haploidentical hematopoietic stem cell transplantation followed by post-transplant cyclophosphamide in adult T-cell leukemia/lymphoma. Clin Case Rep 8: 1553-1559, 2020.

125. Natarajan V, Bandapalli OR, Rajkumar T, Sagar TG and Karunakaran N: NOTCH1 and FBXW7 mutations favor better outcome in pediatric South Indian T-cell acute lymphoblastic leukemia. J Pediat Hematol Oncol 37: E23-E30, 2015.

126. Valliyammai N, Nancy NK, Sagar TG and Rajkumar T: Study of NOTCH1 and FBXW7 mutations and its prognostic significance in South Indian T-cell acute lymphoblastic leukemia. J Pediatr Hematol Oncol 40: e1-e8, 2018.

127. Jenkinson S, Koo K, Mansour MR, Goulden N, Vora A Mitchell C, Wade R, Richards S, Hancock J, Moorman AV, et al: Impact of NOTCH1/FBXW7 mutations on outcome in pediatric T-cell acute lymphoblastic leukemia patients treated on the MRC UKALL 2003 trial. Leukemia 27: 41-47, 2013.

128. Asnafi V, Buzyn A, Le Noir S, Baleydier F, Simon A, Beldjord K, Reman O, Witz F, Fagot T, Tavernier E, et al: NOTCH1/FBXW7 mutation identifies a large subgroup with favorable outcome in adult T-cell acute lymphoblastic leukemia (T-ALL): A Group for Research on Adult Acute Lymphoblastic Leukemia (GRAALL) study. Blood 113: 3918-3924, 2009.

129. Malyukova A, Brown S, Papa R, O'Brien R, Giles J, Trahair TN Dalla Pozza L, Sutton R, Liu T, Haber M, et al: FBXW7 regulates glucocorticoid response in T-cell acute lymphoblastic leukaemia by targeting the glucocorticoid receptor for degradation. Leukemia 27: 1053-1062, 2013.

130. Saito Y, Aoki Y, Muramatsu H, Makishima H, Maciejewski JP Imaizumi M, Rikiishi T, Sasahara Y, Kure S, Niihori T, et al: Casitas B-cell lymphoma mutation in childhood T-cell acute lymphoblastic leukemia. Leuk Res 36: 1009-1015, 2012.
131. Huang HL, Weng HY, Wang LQ, Yu CH, Huang QJ, Zhao PP, Wen JZ, Zhou H and Qu LH: Triggering Fbw7-mediated proteasomal degradation of c-Myc by oridonin induces cell growth inhibition and apoptosis. Mol Cancer Ther 11: 1155-1165, 2012.

132. Zheng R, Li M, Wang S and Liu Y: Advances of target therapy on NOTCH1 signaling pathway in T-cell acute lymphoblastic leukemia. Exp Hematol Oncol 9: 31, 2020.

133. Chiba S: Notch signaling in stem cell systems. Stem Cells 24: 2437-2447, 2006.

134. Tan SH, Bertulfo FC and Sanda T: Leukemia-initiating cells in T-cell acute lymphoblastic leukemia. Front Oncol 7: 218, 2017.

135. Belmonte M, Hoofd C, Weng AP and Giambra V: Targeting leukemia stem cells: Which pathways drive self-renewal activity in T-cell acute lymphoblastic leukemia? Curr Oncol 23: 34-41, 2016.

136. Gordeeva O: TGF $\beta$ family signaling pathways in pluripotent and teratocarcinoma stem Cells' fate decisions: Balancing between self-renewal, differentiation, and cancer. Cells 8: 1500, 2019.

137. Ma L, Wang Y, Hui Y, Du Y, Chen Z, Feng H, Zhang S, Li N, Song J, Fang Y, et al: WNT/NOTCH pathway is essential for the maintenance and expansion of human MGE progenitors. Stem Cell Reports 12: 934-949, 2019.

138. Rho JY, Bae GY, Chae J, Yu K, Koo DB, Lee KK and Han YM: Transcriptional Properties of the BMP, TGF- $\beta$, RTK, Wnt, Hh, Notch, and JAK/STAT signaling molecules in mouse embryonic stem cells. Reproductive Dev Biol 30: 143-156, 2006.

139. Ding D, Lim KS and Eberhart CG: Arsenic trioxide inhibits Hedgehog, Notch and stem cell properties in glioblastoma neurospheres. Acta Neuropathologica Communications 2: 31, 2014.

140. Liu H, Zhu L and Liu YH: Effect of FBXW7 and NOTCH1 mutations on prognosis of patients with adult acute $\mathrm{T}$ lymphoblastic leukemia. Zhongguo Shi Yan Xue Ye Xue Za Zhi 26: 1294-1300, 2018 (In Chinese).

(c) (i) () This work is licensed under a Creative Commons cc) Attribution-NonCommercial-NoDerivatives 4.0 International (CC BY-NC-ND 4.0) License. 